\title{
Analysis on Task-Based Network Teaching of College English \\ Intensive Reading Course
}

\section{Xinli Shi}

\section{School of Foreign Languages, Ningxia Normal University, Guyuan, 756000, China}

\begin{abstract}
In the teaching for English Major at college, English intensive reading course, as an important foundation course, should be highly valued. To effectively improve the teaching effects, the application of task-based teaching method in the teaching is discussed. Based on the analysis of task-based teaching method and its theoretical basis, the building and implementation of tasked-based network teaching method of college English intensive reading course is elaborated in this paper. The student-oriented teaching concept is highlighted to better improve students' English language application ability and promote their all-around development.
\end{abstract}

Key words: Task-based; English intensive reading course; network teaching

English intensive reading course, which has always been an important foundation base of English major at college, is an important content of English teaching and also the key course to improve students' English ability and level. English intensive reading course is mainly a comprehensive English skill course, aiming at cultivating and improving students' English comprehensive application ability. At the same time, its teaching effect has direct influences on students' TEM4 and TEM8, so it is required to pay attention to the design of teaching content and application of teaching method, comprehensively improve the teaching effects and enhance students’ English level and ability. 


\section{Task-based teaching method and its theoretical basis}

(I) Task-based teaching method

Task-based teaching method is one based the task-based syllabuses, with students' activity as the class subject and students' development as the teaching goal. In implementing the task-based teaching method, the following things should be done, such as semantic expression, simulation of real environment and clear input of communication results and at the same time, the design of course content should be stressed to get good teaching effects. The task-based teaching method is mainly an activity with goal as the orientation and foreign language as an medium, in which the task activity cannot leave situation and foreign language activity will involve in some inherent social dialogues of human. Generally, the implementation of task-based teaching method has five characteristics: first, activity. In the classroom teaching, students fulfill the task by virtue of language medium activity so as to learn the relevant language knowledge. Second, situation. The situation can not only stimulate students' learning interest, but also mobilize their learning initiative to effectively improve the teaching effects. Third, dialogicality. In the task-based teaching method, the dialogicality and interaction are fully embodied. Generally, teacher-student interaction and student-student interaction are completed by dialogue. Students cannot only complete the cognitive activity, but also conduct social activity in using the language. Fourth, constructivism. The task-based teaching method aims at completing the language teaching by task activity to make students master the language rule and scene and use them flexibly. Fifth, instrumentality. Language is mainly an instrument for students to complete the task activity. In the classroom teaching activity, the students are required to use the English language in a special environment to achieve the goal of task activity and get good teaching effects.

(II) Theoretical basis

1. Language acquisition theory

The language learning and development of an individual is called language acquisition. People's research on language acquisition is mainly to know the rule and essence of language learning so as to development the specific language learning 
method. In the language acquisition theory, it is thought the pure knowledge memory cannot ensure the accurate application of language and the language application method can be correctly mastered only in repeated practice. In this case, the task-based learning method is proposed and its theory is to change the language learning and application thought into practical teaching model. The task-based teaching method aims at providing good language environment for students and making students complete the language learning in the interactive activity to achieve the expected learning effects.

\section{Constructivism theory}

In the task-based teaching method, "people first" and "students centered" are the core teaching teaching and its philosophical basis is the constructivism theory. Based on psychology, anthropology, philosophy and other science, the theory proposes that the knowledge is developing, subjective and transient and the learning is a psychological construction process that the students conduct reconstruction actively under the action of original cognitive system and external environment. In the constructivism theory, the teaching exchange and cooperation are highlighted and different opinions can be obtained only after continuous exchange so as to perfect the learning construction constantly. Supported by this theory, the implementation of task-based teaching method can provide more language data for students, create good language environment, realize the combination of classroom teaching and extracurricular experience, comprehensively mobilize students' learning interest and initiative and improve the students' language comprehensive application ability so as to achieve the expected teaching goal.

\section{Building and implementation of tasked-based network teaching method of college English intensive reading course}

(I) Stress the task design

The key to implement the task-based teaching method is how to design and implement the task. In designing the task, attention should be paid to the following points: first, the task design must have a clear goal to make students conduct pertinent activity, complete the task and solve the actual problem combined with the goal so as 
to improve their learning effects. Second, the task design should be proper and strongly operable because if the task is too difficult, students may not complete the task, thus losing the confidence in learning to reduce the learning effects; if the task is too simple, students will feel lacking of challenge, thus feeling dull, which is unfavorable to their all-around learning. Therefore, in designing the task, the teacher must comprehensively know students' actual situation to design the task with strong operability conforming to students' development so as to promote their all-around learning. Third, the teaching must start from students' interest and hobby in conducting teaching activity and design some real scene in the classroom teaching to make students have an immersive feeling so as to conduct effective learning, achieve the expected teaching effects and improve their English level. Fourth, the task design should consider the interpenetration between disciplines. The task-based teaching method fully embodies the association and penetration between knowledge. The design of language and skill teaching goal should have broad knowledge scope and large information to make students learn other knowledge in addition to the professional knowledge of English in order to promote their comprehensive development.

(II) Build the teaching model

The teaching model means the stable teaching structure formed under the guidance of educational concept, teaching theory and learning theory. In the network teaching of college English intensive reading course, the students' subjectivity, cooperation, exploration and situationality should be fully embodied and the teaching model conforming to the students' development should be built, with strong operability and interaction to effectively improve the teaching effects. The implementation of task-based teaching model mainly includes the following links: pre-class task design, such as design of learning goal and requirement and development of teaching courseware; implementation of classroom task, such as explanation of text content and exhibition of task achievement; assignment of homework, such as vocabulary test and imitating writing. 
(III) Implementation of teaching method

1. Pre-class task design

In the classroom teaching, the teacher should design real task related to the current learning combined with the teaching goal and course content to mobilize students' learning interest and initiative at maximum and promote their all-around learning. For example, in learning “Legal and Moral Implications of Cloning”, the teacher can put the learning goal, words, phrases, grammar, article structure and other knowledge of this text on the Internet to make students have a preliminary understanding. Then, the teacher can put forward some topics for discussion around the theme, for example, ask the students to conduct discussion on clone technology by groups to make them actively collect and analyze the relevant data, construct the corresponding knowledge system, effectively solve the practical problem and complete the task. Next, the teacher can compile the words of this text into a word list and exercise and put them on the Internet, for example, make students master the key words and understand the relevant synonym, antonym and set phrase by gap filling, to enrich their professional knowledge and improve their performance. Finally, the teacher can make full use of the network environment and multimedia technology to develop exquisite teaching courseware and then put it on the Internet to make students conduct independent learning. The teaching courseware mainly includes analysis of article structure, explanation of words, elaboration of main idea, imitative writing of structure and other contents. When the students ask a questions, a conclusion can be made by discussion and QQ, forum and other forms can be used to promote students' exchange and comprehensively improve their learning effects.

\section{Implementation of classroom task}

In the network teaching of college English intensive reading course, it is required to develop reasonable multimedia courseware according to students' actual language level and full combined with the teaching goal and requirements to explain the teaching contents, such as article structure, main idea of each paragraph, main idea, words and grammar in order to help students further understand the teaching content and master the relevant words and grammar, thus laying a solid language foundation 
for students' further study. For example, in learning “Legal and Moral Implications of Cloning”, there are many words and phrases that should be mastered, such as implication, plain, draft and come to life, so the teacher can develop the multimedia courseware according to these contents to explain the meaning of words and phrases and conduct illustration to deepen students' impression and improve the learning effects. For example, as to come to life whose meaning is be alive or vivid, so the teacher can ask students to translate “我一提到去国外旅游, 孩子们顿时显得兴致勃 勃” with this phrase, then give the correct translation, "When I mentioned our plans for a trip abroad, the kids came to life at once” and conduct explanation to make them understand, memorize and use flexibly. At the same time, the teacher can ask questions about the teaching points and difficulties to make students have an intuitive understanding of the teaching content. In addition, the teacher should immediately answer students' questions. Of course, QQ, forum and other forms can be used to make students have a comprehensive understanding of teaching contents. Besides, each group can report their study of theme by courseware and mobilize the group members' initiative in participation to ensure the smooth completion of reporting. After reporting, other groups can ask questions and conduct objective evaluation. In the whole process of reporting, the teacher should evaluate each group and their members and answer and guide the relevant questions to make students have a thorough understanding of teaching contents and achieve the expected learning goal. Finally, the teacher should conduct effective summarization after reporting to promote the improvement of teaching effects.

\section{Assignment of homework}

After explaining the teaching contents, the teacher can ask students to complete the responding homework on Internet. Doing homework, students should be independent and not copy the homework of others. After submitting the homework, the teacher should carefully check and correct the homework. At the same time, the teacher can assign the summary writing exercise to check the students' mastering of article content. The summary writing exercise can be completed by groups under the leadership of group leader after effective communication and evaluation and the 
exercise results should be recorded. In addition, the teacher can assign the imitative writing exercise of article structure. After completing the imitative writing, the students should send it to the teacher by e-mail, which will be corrected randomly and then commented by the teacher in the next class. The teacher should also mobilize students' participation for comment. In this project, not only the expected teaching contents are completed, but also the students can know their level and then make improvement so as to get good learning effects.

\section{Conclusion:}

In conclusion, in the network teaching of college English intensive reading course, to get better teaching effects, it is required to pay attention to the building and implementation of task-based teaching model, give full play to students’ leading role in learning and the teacher's leading role in teaching, and design the task activity conforming to students' development according to the teaching content to promote students' all-around learning, improve their English level and ability and let them use English language flexibly, thus laying a solid foundation for their future learning and work.

\section{References:}

[1] Li Jianjun, Liu Cuilan. Application of Task-Based Teaching in English Intensive Reading Course[J]. Journal of Inner Mongolia Normal University(Educational Science), 2014(05).

[2] Jiang Dongyan. Exploration of Task-Based Teaching Model of English Intensive Reading Course under Multiple Intelligence Theory[J]. Journal of Jilin Teachers Institute of Engineering an Technology, 2011(08).

[3] Qi Hong.Research on Application of Task-Based Language Teaching Model in College English Intensive Reading Course[J]. Research on Urban Construction Theory (Electronic), 2014(26).

[4] Fan Feng. Building of Task-Based Teaching Model of College English Intensive Reading Course under Multimedia Network Environment[J]. Education and Vocation, 2011(30). 
[5] Li Qing. Application of Task-Based Teaching Method in Teaching of English Intensive Reading Course[J]. Journal of Hebei Polytechnic University: Social Science Edition, 2012(05).

[6] Fu Yanhong. Discussion on Task-Based Teaching Model of College English Intensive Reading Course under Network Environment[J]. Journal of Hubei Correspondence University, 2012(04).

[7] Liu Siyang. Research on Application of Task-Based Teaching Method in Teaching of English Intensive Reading Course and Its Practice[J]. Journal of Jilin Institute of Chemical Technology, 2013(06).

[8] Hu Xiaohong, Kong Jingfang. Cultural Introduction of College English Intensive Reading Course Under Task-Based Teaching Concept[J]. The Science Education Article Collects, 2013(05).

[9] Fu Yanli. Application of Task-Based Teaching Method in Teaching of English Intensive Reading Course[J]. Journal of Liaoning Educational Administration Institute, 2012(04) 